\title{
Friction and Wear Behaviour of Composite Materials Containing Organic Components
}

\author{
ANA SOCALICI ${ }^{1 *}$, ERIKA ARDELEAN ${ }^{1}$, LIVIU PASCU2 ${ }^{2}$, VASILE PUTAN ${ }^{1}$ \\ 'Univesity Politehnica Timisoara, Faculty Engineering of Hunedoara, 5 Revolutiei Str., 331128, Hunedoara, Romania \\ ${ }^{2}$ Technical College of Railway Transportation Anghel Saligny, 137 National Road, 335900, Simeria, Romania
}

\begin{abstract}
The paper presents the experiments performed in the laboratory and the results obtained on friction and wear behaviour of the composite materials for the manufacture of brake shoes used for driving and towed rolling stock. The tribological research of these samples made of composite material with organic components aimed to determine the influence of certain material factors and operating regime parameters on the tribological properties of the tested samples. The brake shoes made of composite materials oneusesto replace the conventional cast iron brake shoes, to reduce the noise. The future research will focus on finding composite materials with superior properties compared to the currently used ones, and lower costs.
\end{abstract}

Keywords: composite, organic materials, friction coefficient, resistance to wear, brake shoes

The European Union has one of the most dynamic transport systems in the world, and the growing noise pollution are among the main current challenges facing it [1]. The protection against environmental noise is one of the main environmental issues in Europe, and by the Directive 2002/49/EC [2] is aimeda common approach for avoiding, preventing or reducing the harmful effects caused by exposure to environmental noise. The Directive concerns a development of measures to reduce the noise emitted by major sources, especially vehicles, aircrafts, roads and rail infrastructure. The European Commission recommends getting composite materials for brake shoes with superior properties, to significantly reducing the costs and noise.

The process of replacing the railway fleet is very expensive, so we try to find solutions to mitigate the noise by measures applied directly to the noise sources $[3,4]$. Such a measure, which is considered the most costeffective one, is to replace the conventional brake systems by using brake shoes made of composite materials, developed to replace the conventional cast iron brake shoes, which are an important source of noise. They are effective in reducing the noise (by $10 \mathrm{~dB}$, equivalent to $50 \%$ of the noise produced by the cast iron brake shoes) [5]. The brake shoes made of composite materials have different braking properties from those of the conventional ones.

The research conducted [6-10] on obtaining composite materials (metal, non-metallic or ceramic matrix) for brake shoes led to obtaining and equipping the rolling stock with quiet ones. The K-type brake shoes are made of organic composite materials and have different braking properties compared to the conventional brake shoes [8]. They are effective in terms of noise reduction, representing a proven technology used for new wagons, but which entails high costs for retrofitting. The LL-type brake shoes require just minor adjustments of the braking system, they have braking properties quite similar to those of the cast iron ones, and are made of either organic composite material or sinter metals [9]. The conditions imposed on these materials are [6]: high friction coefficient; small variation of the friction coefficient with the vehicle speed, maintaining the properties at high temperatures, and high efficiency.
Such materials used in the railway sector (Railways vehicles SNCF, TGV-PSE) in Europe are $[6,11]$ :

- material cod K - Organic matter (5-50\%), mineral material $(50-95 \%), 0.25$ friction coefficient, $450^{\circ} \mathrm{C}$ maximum temperature;

- material cod L - Organic matter (5-50\%), mineral (50$95 \%$ ) - difference of concentration, 0.17 friction coefficient, $500^{\circ} \mathrm{C}$ maximum temperature.

The braking process is also influenced by a number of random factors, such as weather condition (fog and drizzle) and cleanliness of the railway track. These factors adversely affect the adhesion between wheel and rail, being found experimentally that, under the same moisture conditions, the braking distance may vary $[6,12]$. This is due to the braking system, the inertia of the braking system, but especially the material used for making the brake shoe.

Considering these, particular attention should be paid to the friction and wear behaviour of the new composite materials, resulted from experimental research [13-16].

\section{Experimental part}

The paper presents the laboratory experiments carried out and the results obtained on friction and wear behaviour of the samples made of composite materials with organic components for the manufacture of brake shoes for driving and towed rolling stock.

To obtain samples of composite materials and to assess them tribologically, we went through the following stages [11]:

- Mould manufacture;

- Setting out the recipe components;

- Creating our own composite material recipes;

- Tribological behaviour assessment of the materials made on tribotester based on the friction and wear parameters;

- Assessing the influence of test parameters (speed, sliding length, strength and material) on the tribological parameters;

- Analysis of tribological processes in the surface layer using non-destructive methods;

- Analysis results interpretation.

We made 6 experimental samples of composite material using: novolac, hexamethylenetetramine, sulphur, carbon fibre, graphite, aluminium powder, brass powder

*email:virginia.socalici@fih.upt.ro 


\begin{tabular}{|c|c|c|c|c|c|c|c|}
\hline No. & Component recipes, \% & \multicolumn{6}{|c|}{ Recipes } \\
\cline { 3 - 8 } & & P1 & P2 & P3 & P4 & P5 & P6 \\
\hline 1 & Novolac & 23 & 23 & 22 & 19 & 40 & 20 \\
\hline 2 & Hexamethylenetetramine & 4 & 4 & 3 & 4 & 5 & 4 \\
\hline 3 & Sulphur & 5 & 6 & 6 & 7 & 0 & 6 \\
\hline 4 & Carbon fibre & 0 & 0 & 0 & 0 & 10 & 0 \\
\hline 5 & Graphite & 10 & 9 & 9 & 12 & 15 & 15 \\
\hline 6 & Aluminum powder & 14 & 14 & 16 & 15 & 10 & 20 \\
\hline 8 & Brass powder & 13 & 14 & 14 & 15 & 20 & 15 \\
\hline 10 & Rubber & 31 & 30 & 30 & 28 & 0 & 20 \\
\hline
\end{tabular}

and rubber. Components of the recipes are shown in table 1.

To obtain the test specimens (disc type), we used metal moulds. The amounts of recipe components were determined by calculation and preliminary tests. We heated a portion of the phenolic resin until the temperature reached $70^{\circ} \mathrm{C}$, and then gradually incorporated all other components of the recipe. The homogeneous distribution of the components is a fundamental requirement to obtain a high quality composite material. The composite material placed inside the mould was subjected to cold pressing using a hydraulic press. The specimens (along with the mould) were thermally treated by maintaining them for 20 minutes at a temperature of $200^{\circ} \mathrm{C}$. The experimental specimens obtained are shown in figure 1.

The recipes for experimental composite materials included in this study were developed and designed to highlight the influence of the components on the tribological behaviour under a dry regime. The tribological research conducted on composite material samples aimed to determine the influence of certain material factors (concentration and nature of the constituents) and operating regime parameters (pressing force, sliding speed, testing time, and friction regime) on the tribological properties of tested samples, processes occurring at shallow depth, and possibilities of modelling in the desired way.

We analysed the evolution process of the friction coefficient and a wear parameter.
Table 1

COMPONENT RECIPES
The tribological testing device is a universal tribometer (UMT-2). The module can be fitted on this tribotester to carry out the pin-on-disk tests, studying in this way the contact between the two specimens. The equipment allows rotating the disc while the pin is steady and can only move vertically and horizontally to position itself relative to the disc. The pin can be loaded with the adjustable pushing forces. The universal tribometerUMT-2 (CETR ${ }^{\circledR}$, USA) enables carrying out the pin-on-disk tests and watching the variation of control parameters (the normal force $F_{N^{\prime}}$ which is denoted by $F_{x}$ in device software), as well as the measured parameters, which can be selected as needed (friction force, friction coefficient, acoustic emission, distance between the two triboelements, denoted by Z). The tribotester dedicated software shown in figure 2 enables viewing the measured and calculated parameters [11].

For each gear sliding ratio, we calculate the required time to cover the distance of $1500 \mathrm{~m}$, under laboratory conditions. Each test is carried out at a radius of $25 \mathrm{~mm}$ from the centre of the disc to the pin axle, on each disc appearing a single trace of wear. The wear was measured for each disc, separately (the wear of the metal pin, made of bearing steel, being negligible), as mass loss between the value measured initially and the value measured at the end of the test. The samples were cleaned with alcohol, dried and weighed. We carried out two successive weights and took into account their average.
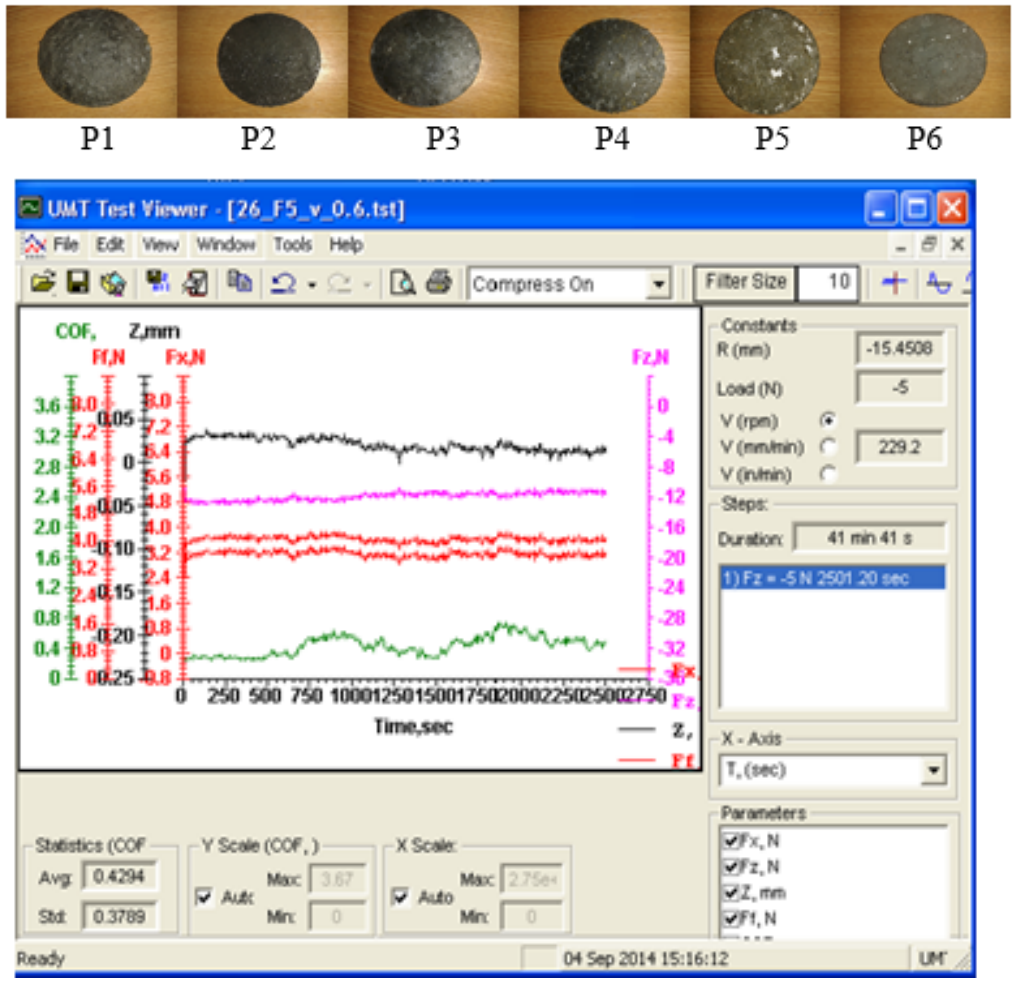

Fig.1. Experimental specimens made of composite material
Fig. 2 Parameters measured during the tests, seen on the tribometer display [11] 


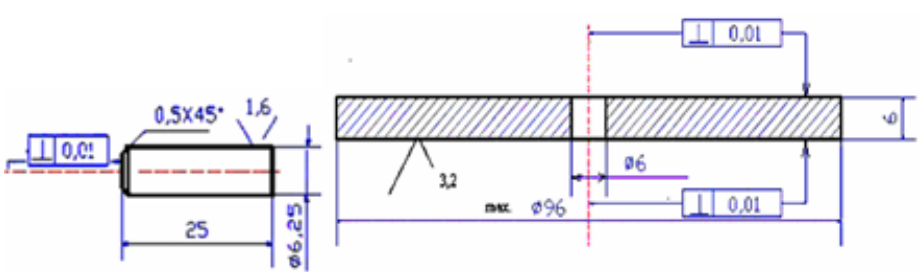

a.

b.

The studied materials are tested under dry sliding conditions, taking into account average normal pressures of $0.17 \mathrm{MPa}$ and $0.34 \mathrm{MPa}$, sliding speeds $\mathrm{v}=0.4 \mathrm{~m} / \mathrm{s}, 0.6$ $\mathrm{m} / \mathrm{s}$ and $0.8 \mathrm{~m} / \mathrm{s}$, and using the experimental discs (composite material) and bearing steel pins ( $R a=0.6$ $0.8 \mu \mathrm{m})$.

In figures 3 are show the shape and dimensions of the tested triboelements [11].

Following the completion of tests, we obtained the testing data in a text file, as well as the parameter graphics recorded by the tribometer computer software.

\section{Results and discussions}

Regarding the friction coefficient variation related to the analysed samples, the experimental data afferent to the loads $F=5 \mathrm{~N}$ and $F=10 \mathrm{~N}$, sliding speeds $v=0.4 \mathrm{~m} / \mathrm{s}$, $0.6 \mathrm{~m} / \mathrm{s}$, and $0.8 \mathrm{~m} / \mathrm{s}$, obtained in a text file from the tribometer computer software, were imported and processed in Excel spreadsheet, and the results were graphically presented in the figures 4-5.

Analysing the friction coefficient variation when testing the samples under the same load $(F=5 N)$, we found the following:

- The friction coefficient variation at the beginning of friction tests is explained by the discontinuous contact
Fig. 3. Shape and dimensions of the steel pin (a) and experimental samples (b) [11]
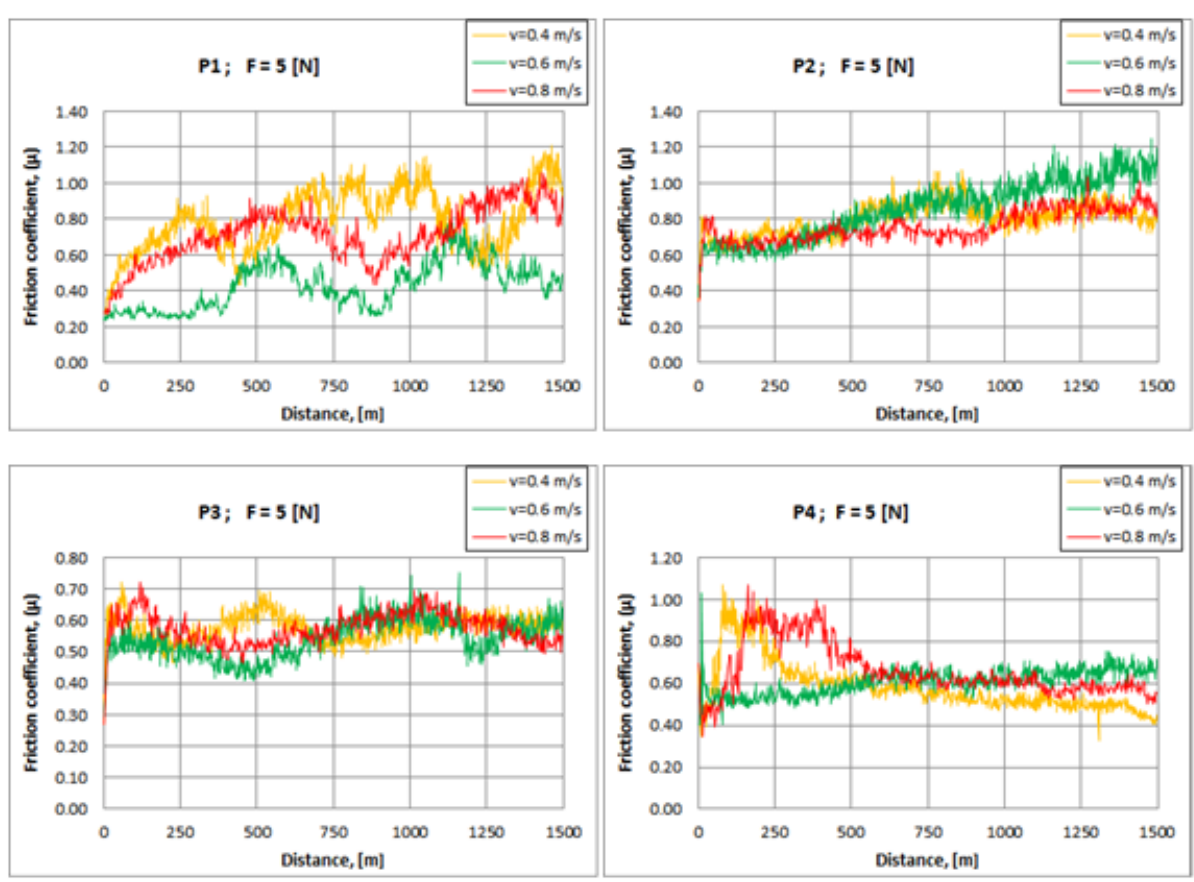

Fig. 4 Friction coefficient obtained when testing the samples, for $\mathrm{F}=5 \mathrm{~N}$

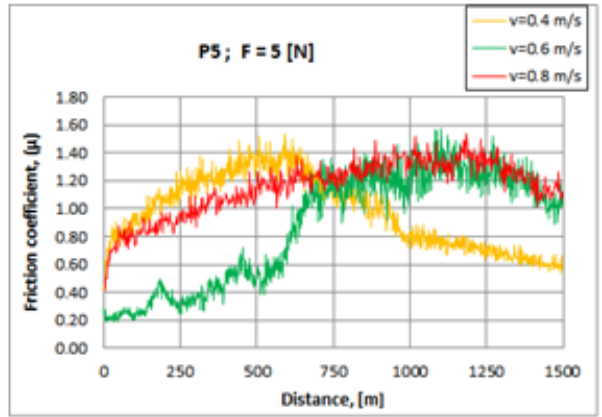

MATERIALE PLASTICE $\bullet 54$ No. $2 \bullet 2017$ between the pin and disc, caused by the irregularity of the front surface of the disc-shaped sample;

- The friction coefficients have values above 0.4 at all the analysed experimental samples, leading to increased braking efficiency;

- At the sample P6, there is a continuous increase of the friction coefficient during the test, with positive effect on the duration of the braking process.

Analysing the friction coefficient variation when testing the samples under the same load $(\mathrm{F}=10 \mathrm{~N})$, we found the following:

- When increasing the workload, at the same sliding speed, the friction coefficients are decreasing, but they become stable over time;

- At the sample P4, almost at the end of the test, the friction coefficient increases towards the value of 0.8;

- The load increase at the sliding speed of $0.6 \mathrm{~m} / \mathrm{s}$ does not change essentially the variation of the friction coefficient. However, at some samples, it decreases a bit, but keeps a fairly constant variation;

- All samples had a relatively constant variation of the friction coefficient throughout the testing process;

- The friction coefficient decreased with increasing load and speed at the samples 1 and 5, but remained above 0.4 at the other samples.

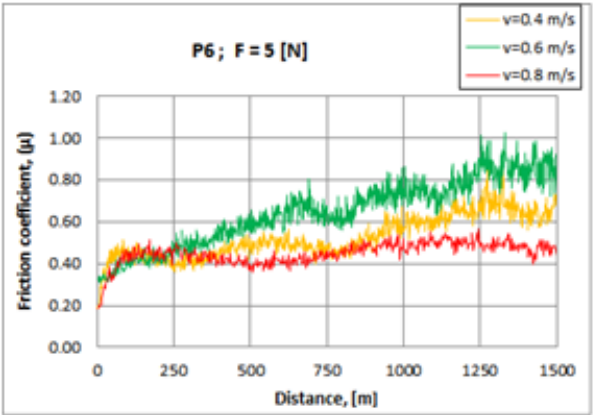

http://www.revmaterialeplastice.ro 

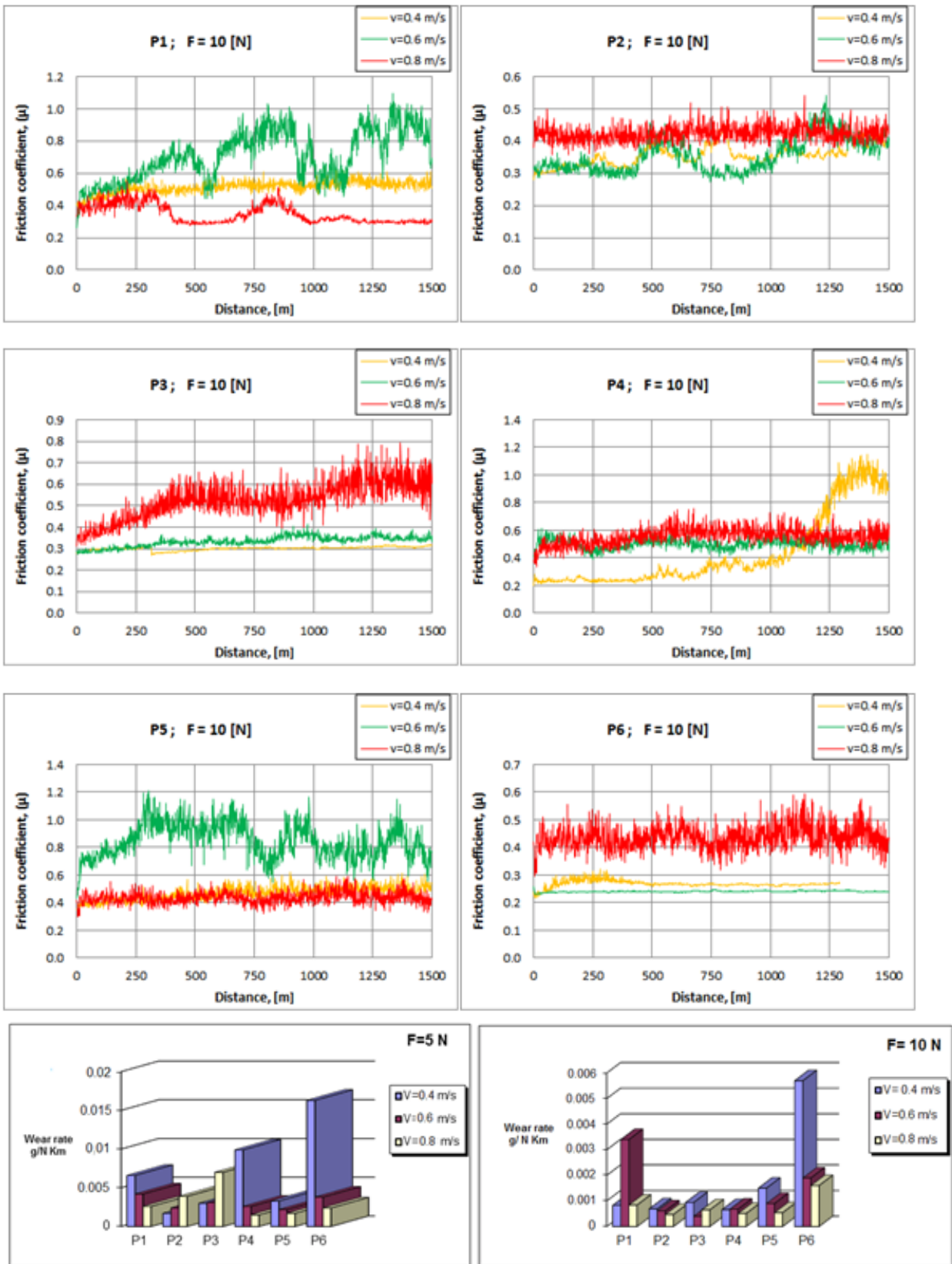

Fig. 5. Friction coefficient obtained when testing the samples, for $\mathrm{F}=10 \mathrm{~N}$
Regarding the wear parameter variation at the experimental samples, we analysed by linear wear rate of the samples at various pressures and sliding speeds.

The wear rate is calculated using the relationship [11]:

$$
W_{\varepsilon}=\frac{\Delta_{m}}{F \cdot L},[\mathrm{~g} / \mathrm{N} \cdot \mathrm{km}]
$$

where:

$$
\Delta_{m}=m_{i}-m_{f}[\mathrm{~g}] ;
$$

$m_{i}^{m}$ - initial wéight of the sample;

$m_{f}$-final weight of the sample, resulted after weighing it using an electronic weighing machine;

$F$-normal force applied on the pin;

$L$ - sliding distance $(L=1500 \mathrm{~m})$.

The wear experimental data, obtained using the normal force $F=5 \mathrm{~N}$ and, respectively, $\mathrm{F}=10 \mathrm{~N}$, a constant sliding distance $L=1500 \mathrm{~m}$ and three sliding speeds $(0.4 \mathrm{~m} / \mathrm{s}, 0.6$ $\mathrm{m} / \mathrm{s}$ and $0.8 \mathrm{~m} / \mathrm{s}$ ), were processed in Excel spreadsheet, and the results are graphically presented in the figure 6 .

Analysing the wear parameter variation, we found the following:

- The wear rate decreases with increasing sliding speed and workload;
- The samples P2, P4, P5 and P6 have the best wear behaviour;

- The samples P1 and P3 are influenced to a small extent by the workload increase;

- Regarding the sample $\mathrm{P} 1$, the explanation for the slight increase in wear rate with increasing workload lies in the lower sulphur content of the sample, which affected the tire behaviour.

\section{Conclusions}

By analysing the experimental and obtained data, we can say that:

- The applied experimental methodology enables the tribological characterisation of the experimental composite materials investigated;

- When increasing the sliding speed, at the same load ( $F$ $=5 \mathrm{~N})$, there is an increasing trend of the friction coefficient with increasing distance covered, at most samples;

-The friction coefficients have good values, except for the sample P1;

-The approximately constant variation of the friction coefficient along the working distance is maintained throughout the tests; 
-The experimental materials have a verygood tribological behaviour, a higher friction coefficient than the composite materials used in industry for the manufacture of brake shoes, as well as a lower wear.

The further analysis of the surface layer enables us to find the explanation for the values of friction coefficient and wear parameters and to assess the condition of worn surfaces and the dispersion of filler materials. The wear must be analysed in relation to the applied loads, sliding speed and environment. Damage can occur under static or dynamic conditions, called tribo-destruction. This wear type is manifested by scratching and detaching particles from the softer layer of the brake shoe, caused by the harder protrusions of the superficial layer of the wheel rim. The wear process can be also initiated by hard particles which, incidentally, can penetrate the clutch contact surface which, by entrainment, can differently scratch the surfaces, depending on their mechanical properties.

The braking capacity depends on the quality of materials and their properties (the friction coefficient, independent of speed and moisture, must withstand temperatures up to $400^{\circ} \mathrm{C}$, no structural changes occurring in the process, it must be resistant to wear, and the friction coefficient must range between 0.30 and 0.40 throughout the breaking process).

The future research and investigations on braking systems to be fitted in high-speed rail vehicles, will focus on finding materials whose friction coefficient is independent of speed and atmospheric conditions (rain, ice, etc.).

\section{References}

1. *** EU Commission Decision 2006/66/EC concerning the technical specification for interoperability relating to the 'material stock - noise of the conventional rail system.
2. *** Directive 2002/49/CE, JO L 189, 18.7.2002, p. 12.

3. SOCALICI, A., PASCU, L., ARDELEAN E., POPA, E, Researches on obtaining composite materials to be used in manufacturing brake pads, International Conference on Applied Sciences, ICAS 2015, Wuhan, PEOPLES R CHINA, Volume 106, 2015, p. 012015

4. GATLAN, A., Noise pollutionin the railway and urban rail, Bulletin AGIR, 1, 2012, p. 49.

5. OCNARESCU, C., TONOIU, S., CATANA, M., OCNARESCU, M., Mat. Plast, 52, no.4, 2015, p.510

6. DUNGAN, L.,DUNGAN, M., Materials used in couplings mechanical friction breking system of high speed railway vehicles, Bulletin AGIR, 2-3, 2010, p.121

7. TOKAR, A., NEGOITESCU, A., ADAM, M., TOKAR, D., Mat. Plast, 51, no.4, 2014, p.432

8. *** UIC SET 07/2012 Design rules of composite brake blocks (K)

9. *** UIC SET 07/2013 Rules for use of composite brake blocks (LL) 10. MARIES, Gh.R.E., Mat. Plast, 52, no.1, 2015, p.32

11. PASCU, L., PhD thesis, Researches on Improving the Quality of Brake Shoes Meant for Use with the Rolling Stock, Politehnica Timisoara, Romania, 2015

12. BOTAN, M., DUMITRU, D., PIRVU, C., DELEANU, L., Mat. Plast, 52, no.1, 2015, p.20

13. BARTON, D.C., Modelling of materials for automotive braking, Materials Technology, 49 no. 6, 2004, p.379

14. GEORGESCU, C., DELEANU, L., BOTAN, M., Dry sliding of composites with PBT matrix and micro glass beads on steel, Industrial Lubrication and Tribology, 66 no. 3, 2014, p.424.

15. NEHARKAR SURESH, P., PATIL, R.J., SONAWANE, P.R., Study of friction and wear for optimization of disc break material for reduction of brake sound, Intemational J ournal of Research in Aeronautical and Mechanical Engineering, 2 no.6, 2014, p.137.

16. LETOURNEAUX, F., AUBIN, F., Acoustic Specification of Composite Brake-Blocks for Railway vehicles, Euro Noise, 31 May - 3 June, Maastricht, 2015, p.2671

Manuscript received: 7.07 .2016 